\title{
JUDEIDADE(S) E IDIOMA: NARRATIVAS DA APORIA EM JACQUES DERRIDA
}

Maria Angélica Deângeli

Doutoranda Unesp/SJRP

\begin{abstract}
RESUMO
Se, por um lado, é possível, por meio de um trabalho de rastreamento de traços ou de mapeamento de rastros, ler as marcas de uma "judeidade em suspenso" e de um idioma sempre “por vir” em Jacques Derrida, por outro, essa pretensa visibilidade só pode transparecer na oscilação e na “indecidibilidade” da escritura do próprio Derrida. Escritura marcada, então, pela herança inapagável da tripla dissociação histórico-cultural de um “judeu-franco-magrebino” que pertence sem pertencer à sua própria herança, e que o leva a dizer, sem estar certo de poder dizê-lo, que a língua francesa é sua única pátria. ${ }^{1}$ Na dúvida permanente entre os vários “entre” que constituem as "entre-narrativas” de Jacques Derrida, situamos os questionamentos deste artigo, a saber: como articular, na aporia desde sempre anunciada, as judeidades de Jacques Derrida no corpus passional e intraduzível de um idioma em língua francesa e de língua francesa? Como ler as entrelinhas dessa judeidade que se entregou (sem se render) ao mutismo? Como descobrir no silêncio dessa língua os segredos de seu idioma? Desta forma, a partir das leituras de Le monolinguisme de l'autre (1996) e de “Abraham, l’Autre” (2003), pretendemos esboçar os contornos de uma reflexão cujo traço principal é o devir de sua própria interrogação.
\end{abstract}

\section{PALAVRAS-CHAVE}

Jacques Derrida, judeidade(s), idioma, aporia

Arriscaríamos dizer, no risco que comporta todo traço, que em Derrida as astúcias (ruses) da escritura estão intimamente ligadas à questão da língua, mais especificamente, da língua francesa. Uma língua que faz irromper do cerne de seu

\footnotetext{
${ }^{1}$ DERRIDA. Abraham, l'Autre, p. 29.
} 
traçado, num movimento de expropriação absoluta ${ }^{2}$ a "chance” do idioma, do idioma e de sua história ou do idioma enquanto história de seu acontecimento.

Que história podemos, então, contar a partir do traço idiomático da escritura derridiana? - uma escritura tão imprópria aos seus traços. O que se oculta e se exibe no percurso dessa história-escritura, dessa história como escritura? É no jogo do idiomático do que está em jogo (enjeu) que se enunciam as narrativas da aporia em Jacques Derrida.

Para esboçarmos o que pode ser um começo (sem ser a origem) de tais preocupações, comecemos pelo estilo de Derrida, ou melhor, pelo estilo de seu idioma.

Em um colóquio internacional realizado em dezembro de $2000,{ }^{3}$ em Paris, em torno de Jacques Derrida, mais precisamente, sobre questões de judeidades dirigidas a Jacques Derrida, ao ser interrogado sobre seu estilo, ao lhe pedirem uma justificação do que viria a ser o estilo (de) Derrida, o autor tenta uma resposta que o livra (o estilo) do velho debate acadêmico ou, como ele diz, “falocêntrico”, em que o estilo se confundiria com o homem e, nesse sentido, Derrida afirma preferir não ter estilo. ${ }^{4}$

Entretanto, uma questão ligada ao estilo, mas não convertida à categoria tradicional de estilo, e à qual Derrida não se furta, é toda a problemática do idioma e de seu devir aporético. Assim, diz o autor:

O idioma, a idiomacidade - se existir - é aquilo que não é reapropriável; idioma quer dizer em grego o que é próprio: idiotès. Eu avançaria como aporia ou necesssidade lógica que o que é próprio não é apropriável, o que me é próprio é aquilo do qual não posso me reapropriar. Dito de outra maneira, eu serei o último a poder ver meu estilo, de alguma forma. ${ }^{5}$

Derrida seria, então, o último a poder ver seu estilo. Poderíamos, no entanto, nos perguntar qual o lugar desse “último” na frase de Derrida. O último vê menos ou não vê tão bem quanto o primeiro? O último só vê depois do primeiro? Mas, na "aporia ou necessidade lógica” por ele avançadas, haveria um primeiro primeiro que veria antes dos outros primeiros ou, antes, dos primeiros últimos?

\footnotetext{
${ }^{2}$ DERRIDA. Le monolinguisme de l'autre - ou la prothèse d'origine, p. 44.

${ }^{3}$ Os atos do colóquio foram publicados no livro Judéités - questions pour Jacques Derrida (Galilée, 2003), sob a direção de Joseph Cohen e Raphael Zagury-Orly. O texto ao qual nos referimos aqui, do próprio Derrida, intitula-se “Abraham, l’Autre” (p. 11-42).

${ }^{4}$ DERRIDA. Abraham, l'Autre, p. 79.

${ }^{5}$ DERRIDA. Seminario de Barcelona, p. 78, (grifo meu sob o vocábulo último).
} 
A afirmação de Derrida, em seu "estilo” bem derridiano, desobriga-o a decidir por uma ou outra forma de escritura, por um traçado de decidibilidades prévias de uma escritura que, em Derrida, está sempre por vir. Digamos, então, que entre o decidível e o que não se decide, entre a língua e o idioma, a assinatura e o anonimato, o apropriável e o inapropriável, entre todos esses "entre” perseguiríamos algum rastro do estilo ou, se preferirmos, do ritmo de Derrida. Talvez encontremos aí, no ritmo, no íntimo, na entonação da língua e no seu sotaque, a escritura derridiana nos seus traços mais visíveis. E não se trata de uma língua qualquer quando falamos de Derrida, mas de um idioma francês sem o qual ele se sente mais perdido do que nunca:

Por um lado, estou dividido entre as leis da hospitalidade, a saber, o desejo do hóspede (hôte) grato que deveria dirigir-se a vocês em sua língua, e, por outro, meu apego invencível a um idioma francês, sem o qual me sinto perdido, mais exilado do que nunca. ${ }^{6}$

A história desse pertencimento sem pertença à língua francesa, a turbulência histórica dessa história de guerra e de separações (mas também de encontros) marcam a história da desconstrução derridiana. Uma história entre várias histórias que se cruzam e se prolongam numa batida contínua de vida e de morte, como dirá o próprio Derrida:

É preciso talvez, de fato, partir da différance ou da batida, ao invés [de partir] dos pólos da realização ou da morte. O que está do lado da vida estaria, então, do lado da batida? Enquanto bater há vida, e quando não houver mais vida nada mais bate. Não falo da batida do coração, mas do ritmo, dos ritmos. Então, afirmar a vida, dito de outra forma, afirmar o gozo do lado da vida ao invés [de afirmá-lo] do lado da morte, é afirmar a batida, um ritmo no qual há morte, não uma morte que seja oposta à vida, mas uma morte que está lá, que cisalha a vida, que é o ritmo $(. . .)^{7}$

O idioma está do lado da vida - da vida como diferimento da morte e da vida como promessa de uma morte. Vida e morte ou vida-morte que comparecem aqui não

\footnotetext{
6 “Je serais partagé entre, d'une part, les lois de l'hospitalité, à savoir le désir de l'hôte reconnaissant qui devrait s'adresser à vous dans votre langue, et, d'autre part, mon attachement invincicle à un idiome français sans lequel je suis perdu, plus exilé que jamais.” (DERRIDA. Fichus, p. 6).

7 "Il faut peut-être en effet partir de la différance ou du battement, plutôt que des pôles de l'accomplissement ou de la mort. Ce qui est du côté de la vie, est-ce alors du côté du battement? Tant que ça bat il y a de la vie, et quand il n'y a plus de vie ça ne bat même plus. Je ne parle pas du battement du coeur mais du rytme, des rytmes. Alors affirmer la vie, autrement dit affirmer la jouissance du côté de la vie plutôt que du côté de la mort, c'est affirmer le battement, un rytme dans lequel il y a de la mort, non pas une mort qui soit opposée à la vie mais une mort qui est là, qui cisaille la vie, qui est le rytme (...).” (DERRIDA. Seminario de Barcelona, p. 61).
} 
como oposições, como diz Derrida, mas como figurações de um “hífen” dessa escritura idiomática que marca a vida-morte de quem a escreve. Escrever ao ritmo de uma batida que é o próprio ritmo, um ritmo "que cisalha a vida, que é o ritmo...” (qui cisaille la vie, qui est le rytme...).

Mas como perceber esse ritmo? Percebê-lo, na dúvida de sua apreensão, nos rastros de língua, mais precisamente, da língua francesa. A relação traumática com essa língua implicará, para Derrida, o próprio movimento da différance, como citado acima, pois a língua está sempre lá, “sempre já lá”, “sempre ainda lá” 8 e sempre por vir. Mais ainda: "Para que tal língua exista na escritura, própria por vir, é preciso que ela se imprima num corpo idiomático...”. 9

A língua estaria, então, numa relação de corpo a corpo com o outro corpo (ou o corpo do outro), com o corpo de um judeu-franco-magrebino que no corpus da própria língua (sem que esta lhe seja própria) narra a história silenciosa de sua condição originariamente dissociada e para sempre dissociável.

História da história: em 1870, sob a III República, pelo “Decreto Crémieux”, a França outorga a cidadania francesa aos judeus da Argélia; um ato que procurava exibir as "benesses” da colonização francesa para a população local. Como esquecer a corporalidade dessa presença presente na própria ausência? Ou, como dirá Cixous:

O esquecimento é tão intenso, tão bem organizado.

Como lembrar, como se lembrar, (d)o mês de julho 1830, está tão quente, foi ontem, como não se lembrar da força impetuosa do exército, os 37000 homens, munidos pelo ministério da Guerra de um Resumo histórico que permite opor "a verdade" aos "erros" e prometer aos soldados a vitória sobre os Turcos, os Mouros e os outros. É num ontem bem protegido pelo esquecimento que, na noite do dia 4 de julho, o exército atingiu o planalto de El Biar e as encostas que dominavam a oeste o Forte Empereur. ${ }^{10}$

\footnotetext{
${ }^{8}$ DERRIDA. Le monolinguisme de l'autre - ou la prothèse d'origine, p. 101.

9 “Pour qu'une telle langue soit dans l'écriture, propre à venir, il faut qu'elle s'mprime dans un corps idiomatique(...) ” (DERRIDA. Seminario de Barcelona, p. 40).

10 “L’oubli est si haut, si bien organisé.

Comment rappeler, comment se rappeler, le mois de juillet 1830, il fait si chaud, c'est hier, comment ne pas se rappeler le déferlement de l'armée, les 37000 hommes, munis par le ministère de la Guerre d'un Aperçu historique qui permet d'opposer 'la vérité' aux 'erreurs' et de promettre aux soldats la victoire sur les Turcs, les Maures et les autres. C'est un hier bien gardé par l'oubli que, le soir du 4 juillet, l'armée atteint le plateau d'El Biar et les pentes qui dominaient à l'ouest le Fort l'Empereur.” (CIXOUS. Ce corps étranjuif, p. 59-60).
} 
O presente da enunciação se faz presente nesse passado. Um presente-passado que incessantemente violentou a cultura local no local próprio daquela cultura. Em 1940, menos de um século depois, essa mesma França, sob o governo de Vichy, em nome de um Marechal Pétain, confisca-lhes (aos ditos “judeus-magrebinos”) a nacionalidade francesa para, logo depois, em 1944, conceder-lhes novamente o estatuto de franceses.

História única no mundo, como dirá ${ }^{11}$ Derrida, na qual se escrevem as rupturas necessárias e impossíveis da escritura derridiana. O “primeiro paradoxo” e a "aporia do princípio” também se inscrevem nessa dissociação histórica originária, pois, de acordo com Derrida:

O primeiro paradoxo ou a aporia do princípio estão ligadas ao fato de que a experiência da dissociação ou da heterogeneidade disseminal é exatamente aquilo que proíbe a dissociação de se fixar ou de se reconciliar em distinção oposicionais, em fronteira decidível e em diferença estabilizadora. ${ }^{12}$

No princípio mesmo da indecisão é que se conta, então, a história desse judeufranco-magrebino. Difícil, para Derrida, poder distinguir o que diz respeito à sua experiência, ao seu "ser-judeu" daquilo que não se marca em seu trabalho - essa marca que se oculta sem, no entanto, ser o sintoma do recalcamento da letra do Livro (das Sagradas Escrituras). Paradoxos e prevalência originária do sempre “talvez”, do “entre”, do “dentro” e do “fora”. Questões que levam o próprio autor a afirmar:

Como e com que direito distinguir, por exemplo, entre o que de minha experiência diz respeito, de um lado, ao meu "ser judeu" mais íntimo ou mais obscuro, mais ilegível (...) e o que, por outro lado, digamos, parece pertencer, de modo mais legível, ao meu trabalho, a um trabalho público de bom ou mau aluno que não carrega necessariamente nem sempre as marcas visíveis de meu "ser judeu", quer se trate de escritura, de ensino, de ética, de direito ou de política, de comportamento cívico, quer se trate de filosofia ou de literatura. ${ }^{13}$

\footnotetext{
${ }^{11}$ DERRIDA. Abraham, l’Autre, p. 29.

12 "Le premier paradoxe ou l'aporie principielle tient au fait que l'expérience de la dissociation ou de l'hétérogénéité disséminale est cela même qui interdit la dissociation de se fixer ou de s'apaiser en distinction oppositionnelle, en frontière décidable et en différence rassurante.” (DERRIDA. Abraham, l'Autre, p. 25-26).

13 “Comment et de quel droit distinguer, par exemple, entre ce qui de mon expérience touche d'une part à mon 'être juif' le plus intime ou le plus obscur, le plus illisible (...) et ce qui, d'autre part, disons, semble appartenir, de façon plus lisible, à mon travail, à un travail public de bon ou de amuvais élève qui ne porte pas nécessairement ni toujours les marques visibles de mon 'être-juif', qu'il s'agisse d'écriture ou d'enseignement, d'éthique, de droit ou de
} 
A problemática que gira em torno do "ser judeu”, do traço (gramatical) explícito da judeidade, começaria para Derrida, por exemplo, na passagem das marcas gramaticais de pessoas, ou seja, entre o que designa o "eu sou judeu”, "você é judeu”, “nós somos judeus” e um “ele é judeu”. O questionamento sobre a judeidade partiria, desta forma, da dissociação entre os sujeitos - palavra para qual Derrida prefere reservar um sentido "puramente” gramatical ${ }^{14}$ - gramaticais, o que o leva a se perguntar: "Como essas pessoas se traduzem uma na outra e isso seria possível? Podemos autorizar-nos passar de um ‘você é judeu ou judia' a um ‘então eu o sou’?’15

Derrida, ao avançar essas distinções “necessárias mas impossíveis” e, também, insustentáveis sobre o que diz respeito à judeidade, refere-se a uma obra de Sartre intitulada Réflexions sur la question juive (1954), em que este último traça o perfil do que viria a ser o judeu "autêntico" e o judeu "inautêntico". Para descontruir o aparato ideológico defendido por Sartre, Derrida atém-se, primeiramente, ao fato de que em Sartre o judeu é sempre nomeado nas terceiras pessoas (ele, ela, eles, elas.). Essa nomeação, sobre a qual falamos acima, que implicaria a passagem do eu/você/nós para um ele/eles, criaria a ilusão de uma categoria neutra para designar o "ele” judeu. Assim, judeu seria sempre o nome desse outro não inclusivo de si-mesmo. Além disso, segundo Derrida, Sartre se limitaria a uma visão por demais simplista ao avançar a hipótese de uma “judeidade de situação” ou “em situação”. De acordo com Sartre: “O Judeu é um homem que os outros homens consideram Judeu: eis a verdade simples da qual é preciso partir.”16 Ou ainda: “Assim, o Judeu está em situação de Judeu porque ele vive numa coletividade que o considera Judeu.” ${ }^{17}$ Verdade muito simples para Derrida que, de maneira quase espantosa, dirá: "Como se tivesse bastado que o outro me dissesse

politique, de comportement civique, qu'il s'agisse de philosophie ou de littérature.” (DERRIDA. Abraham, l'Autre, p. 12).

${ }^{14}$ DERRIDA. Abraham, l’Autre, p. 15.

15 “Comment ces personnes se traduisent-elles l'une dans l'autre et est-ce possible? Peut-on s'autoriser à d'un 'tu es juif ou juive', à un 'donc je le suis? '” (DERRIDA. Abraham, l'Autre, p. 15).

16 "Le Juif est un homme que les autres hommes tiennent pour Juif: voilà la vérité simple d'où il faut partir.” (Sartre, 1954, p. 83-84 citado por DERRIDA. Abraham, l’Autre, p. 27).

17 "Ainsi le Juif est en situation de Juif parce qu'il vit dans une collectivité qui le tient pour Juif.” (Sartre, 1954, p. 88, citado por DERRIDA. Abraham, l’Autre, p. 27). 
'você é judeu ou um Judeu' para que eu nascesse para minha suposta identidade de Judeu, para o que Sartre chama então minha situação de Judeu.”18

A situação proposta por Sartre, e que constitui o fio condutor de seu trabalho, parece limitar ainda mais a "situação" da judeidade. O autor restringe sua análise aos “Judeus da França”, ao “Judeu francês”, tal como ele próprio afirma:

Se eu quiser saber quem é o Judeu, tenho que, já que é um ser em situação, interrogar primeiramente sua situação sobre ele próprio. Advirto que limitarei minha descrição aos Judeus da França, pois é o problema do Judeu francês que é nosso problema. ${ }^{19}$

Mas o que seria um “Judeu da França” ou um “Judeu francês”? Todo “Judeu da França” seria necessariamente “Judeu francês”? Quem se incluiria (ou seria excluído) nessa categoria? Dizer "um Judeu da França” implicaria dizer "um judeu de língua francesa”? E haveria judeu francês de língua não francesa? E os judeus de língua francesa não francês? Enfim, nos limites dessas categorias não assinaláveis, as quais constituiriam, para Derrida, "uma fronteira metodológica situacional”, 20 injustificável e artificialmente restritiva, nessas bordas (limitantes) estariam fora de campo, segundo Derrida: “(...) todos esses estrangeiros Judeus não-estrangeiros que como eu [como ele, Derrida], se ouso dizer, como os Judeus da Argélia, não eram, de maneira alguma, indecidivelmente, nem franceses nem não-franceses." ${ }^{21}$

Mais uma vez é a questão da língua que se impõe (que se nos impõe). A judeidade chega a Derrida, até Derrida, pela língua, impondo-lhe uma condição originária de dívida e expondo-o a uma "falha congênita",22 que o levam a confessar, num mutismo quase absoluto, seu “não-pertencimento de fato à cultura judaica”, ${ }^{23}$

\footnotetext{
18 “Comme s'il avait suffi que l'autre me dise 'tu es juif ou un Juif' pour que je naisse à ma supposé identité de Juif, à ce que Sartre appelle ma situation de Juif.” (DERRIDA. Abraham, l’Autre, p. 27).

19 “Si je veux savoir qui est le Juif, je dois, puisque c'est un être en situation, interroger d'abord sa situation sur lui. Je préviens que je limiterai ma description aux Juifs de France car c'est le problème du Juif français qui est notre problème.” (Sartre, 1954, p. 73, citado por DERRIDA. Abraham, l'Autre, p. 28).

${ }^{20}$ DERRIDA. Abraham, l'Autre, p. 28.

21 “(...) tous ces étrangers Juifs non-étrangers que comme moi, si j’ose dire, comme les Juifs d’Algérie de ma génération, n'étaient, de mille façons, indécidablement, ni français ni nonfrançais.” (DERRIDA. Abraham, l'Autre, p. 28).

${ }^{22}$ DERRIDA. Abraham, l'Autre, p. 17.

${ }^{23}$ DERRIDA. Le monolinguisme de l'autre - ou la prothèse d'origine, p. 79.
} 
Não se trata mais de saber, como queria Sartre, em que consiste ser um "Judeu autêntico" e um "Judeu inautêntico”, mas, ao contrário, de se interrogar por onde passa ou como chega essa judeidade que nunca, sob nenhuma forma e de nenhuma maneira, poderá pretender uma suposta autenticidade. Não existe uma essência a partir da qual se nomearia o "ser judeu”; só podemos nomear a partir da língua e a língua para Derrida supõe “uma alienação sem alienação”, uma “alienação originária”, tal como ele nos diz:

\begin{abstract}
A alienação não é um acontecimento que tem lugar num dado momento, de tal forma que num dado momento nós seríamos, por exemplo, mestres e possuidores de nossa linguagem e que alguém ou uma força qualquer viesse arrancá-la de nós, a alienação faz parte de nossa experiência da linguagem desde o começo, ela é originária. (...). Como essa alienação não tem história, como ela começa desde a primeira palavra, desde a primeira sílaba, é uma alienação sem alienação, é uma alienação que não pode ser afetada, (...), então, é uma alienação que é inalienável. ${ }^{24}$
\end{abstract}

A alienação faria, então, parte do movimento de expropriação da língua, pois na alienação nada (se) pertence. Tal processo remeteria também ao problema da morada da língua ou da "língua sem morada" (langue à demeure sans demeure). ${ }^{25}$ Mas, se, por um lado, a alienação “não tem história”, por outro, ela está ancorada na historicidade do sujeito, ela começa com o sujeito, está na sua “origem” (enquanto origem da origem) e o "afeta” desde a "primeira palavra”.

No começo existiu, então, a Palavra e a primeira palavra teria chegado até Derrida em francês, nessa língua de outro lugar, do estrangeiro, do outro do outro. Ele tenta se lembrar de como essa palavra teria chegado e se pergunta num exercício de memória:

(...) como a palavra "judeu” (bem antes de "judaísmo" e sobretudo "judeidade") chegou (est arrivé), ${ }^{26}$ chegou até mim (m'est arrivé)

\footnotetext{
24 “ L'aliénation n’est pas un événement qui a lieu à un moment donné, de telle sorte qu’à un moment donné nous serions, par exemple, maîtres et possesseurs de notre langage et que quelqu'un ou qu'une force quelconque viendrait nous le prendre, l'aliénation fait partie de notre expérience du langage dès le départ, elle est originaire. (...). Comme cette aliénation n’a pas d'histoire, qu'elle commence dès le premier mot, dès la première syllabe, c'est une aliénation sans aliénation, c'est une aliénation qui ne peut pas être affectée, (...), donc c'est une aliénation qui est inaliénable.” (DERRIDA. Seminario de Barcelona, p. 51).

${ }^{25}$ Em francês faríamos um uso quase abusive da palavra demeure para simbolizar toda a empreitada da língua em errância: langue qui demeure à demeure sans demeure (língua que permanece para sempre sem morada). (CRÉPON. Langues sans demeure, p. 37).

${ }^{26}$ Derrida joga com os dois sentidos de arriver: "acontecer” e "chegar". Nesse contexto, poderíamos optar pela tradução "de uma palavra que chega" ou "que acontece” A chegada da
} 
como alguém que chega, senão como o primeiro que chega, na língua da minha infância, desembarcando na língua francesa da Argélia das minhas primeiras frases. Eu não alcançarei nesta noite (...) esta anamnese da chegada de "judeu” na minha língua, desse vocábulo que permanece para mim desconhecido, mais profundo em mim do que meu próprio nome, mais elementar e mais inapagável do que qualquer outro no mundo, (...), que está mais perto do meu corpo do que uma vestimenta ou do que meu próprio corpo. ${ }^{27}$

A palavra passa pelo corpo, está mais perto do corpo do que o“ próprio corpo”. Instala-se, penetra, corta-o e deixa marcas de sua existência no corpus da língua. Uma palavra em forma de lei que dita a Lei do corpo circunciso do homem judeu. Mas de que homem (judeu) tratar-se-ia?

Num ensaio consagrado a Jabès, na obra L'écriture et la différence (1967), Derrida se interroga sobre a "identidade” do "judeu”, o destino da judeidade, sobre o risco no qual se incorreria ao “fazer um”, tornar “una” toda política identitária associada ao nacionalismo e ao “comunitarismo”. Mas a saída para Derrida é outra, ao falar de Jabès, ele, então, afirma:

Nessa não-coincidência de si consigo próprio, ele é mais judeu e menos judeu do que o Judeu. Mas a identidade em si do Judeu talvez não exista. Judeu seria o outro nome dessa impossibilidade de ser si. $\mathrm{O}$ Judeu é dilacerado e está, antes de tudo, entre estas duas dimensões da letra: a alegoria e a literalidade. ${ }^{28}$

“Alegoria” e "literalidade” que se dão quanto a Derrida no recurso e no apelo à língua francesa, na nomeação do "ser judeu”. Não existe, então, judeu possível, pois “Judeu” designaria o que está sempre “além”, outra coisa que o conjunto de suas condições de possibilidade, um acontecimento de língua, da língua e, dessa forma, sempre por vir. Derrida, no entanto, afirma ser o "último” dos Judeus (le dernier des

palavra como acontecimento é o que está em jogo no idiomatismo do verbo arriver em francês.

27 “(...) comment le mot ‘juif’ (bien avant 'judaïsme’ et surtout ‘judéité’) est arrivé, m’est arrivé comme un arrivant, sinon comme premier arrivant, dans la langue de mon enfance, débarquant dans la langue française d'Algérie de mes premières phrases. Je n'atteindrai pas ce soir (...) à cette anamnèse de l'arrivée de 'juif' dans ma langue, de ce vocable qui me reste inouï, plus profond en moi que mon propre nom, plus élémentaire et plus innefaçable qu'aucun autre au monde, (...), qui est plus près de mon corps qu'un vêtement et que mon corps même.” (DERRIDA. Abraham, l'Autre, p. 18).

28 "Dans cette non-coincidence de soi avec soi, il est plus juif et moins juif que le Juif. Mais l'identité à soi du Juif n'existe peut-être pas. Juif serait l'autre nom de cette impossibilité d'être soi. Le Juif est brisé et il est d'abord entre ces deux dimensions de la lettre: l'allégorie et la littéralité.” (DERRIDA. Edmond Jabès et la question du livre, p. 112). 
Juifs, que suis je). ${ }^{29}$ Mas o último dos Judeus seria o judeu impossível, aquele que ainda não antecedeu ao primeiro ou aquele cuja condição de possibilidade é sua própria impossibilidade. Aporias derridianas cuja narrativa só pode ser apreendida se levarmos em conta, desde o princípio, a experiência judeu-argelina da impossível propriedade da língua, da língua de um outro não assinável que confessou, embora imaginasse ter se calado, fazer parte daqueles que:

(...) se sentem ao mesmo tempo francês, muito francês, francês por inteiro (sem estar certo de poder dizê-lo, também já me expliquei com relação a isso em outras ocasiões, como Hannah Arendt diz no que concerne à língua alemã, [que] "a língua francesa é minha única pátria”, ainda que a língua francesa, o francês, no irredentismo de seu idioma mais intraduzível, seja no fundo o corpo passional de todas as minhas paixões, mesmo que este corpo tenha se entregado muitas vezes ao silêncio)...”. ${ }^{30}$

Irredentismo de um idioma intraduzível que poderia se traduzir, nas palavras de Cixous, como a história de um corpo “estranjudeu” (étranjuif) ${ }^{31}$ _"estranho-judeu” ou “judeu-estrangeiro"-, como o destino de quem esteve sempre "entre” e “com”: ${ }^{32}$ entre/com a França e Argélia, a língua e o idioma, o estranho e o familiar, o estrangeiro e o nacional, o amor e a guerra, a vida e a morte. Enfim, história daquele que não pode ser e que também não pode não ser.

\footnotetext{
${ }^{29}$ DERRIDA. Circonfession, p. 145.

30 “(...) se sentent à la fois français, très français, français de part en part (sans être sûr de pouvoir dire, je m'en suis expliqué ailleurs, comme Hannah Arendt le dit de la langue allemande, 'la langue française est ma seule patrie', encore que la langue, le français, dans l'irrédentisme de son idiome le plus intraduisible, soit au fond le corps passionnel de toutes mes passions, même si ce corps se voue souvent au silence)...” (DERRIDA. Abraham, l'Autre, p. 29).

${ }^{31}$ A palavra étranjuif, em francês, pode remeter tanto a étrange (estranho) como a étranger (estrangeiro), já que o vocábulo em questão se forma na elisão do ge(r) final de étran(ge)(r) com o "j" de juif. Optamos pela tradução (quase) literal de "estranjudeu" que parece, pelo menos em parte, recobrir os sentidos do neologismo francês. (DERRIDA. Abraham, l’Autre, p. 59).
}

${ }^{32}$ DERRIDA. Abraham, l’Autre, p. 65. 


\section{RÉSUMÉ}

Si, d'un côté, il est possible de lire les traces d'une "judéité en suspens" et d'un “idiome toujours à venir" chez Jacques Derrida, d'un autre, la pretention de cette visibilité ne peut transparaître que dans l'oscillation et dans l'indecidabilité propres à l'écriture derridienne. Une écriture qui est marquée par l'héritage ineffaçable d'une triple dissociation historico-culturelle d'un juif-francomaghrebin qui appartient sans appartenir à sa propre culture, ce qui menera Derrida à dire, sans être sûr de pouvoir le dire, que la langue française est sa seule patrie. ${ }^{33}$ L'objectif de ce travail est donc de mettre en question les judéités de Jacques Derrida, toujours annoncées sous le signe d'une aporie. Pour ce faire, nous partons donc des lectures de Le monolinguisme de l'autre (1996) et de son texte “Abraham, l’Autre” (2003), ce dernier publié lors du colloque international, Judéités: questions pour Jacques Derrida, qui s’est tenu à Paris en décembre 2000.

\section{MOTS-CLÉ}

Jacques Derrida, judéités, idiome, aporie

\section{REFERÊNCIAS}

CIXOUS, H. Ce corps étranjuif. In: COHEN, J.; ZAGURY-ORLY, R. (Org.). Judéités - questions pour Jacques Derrida. Paris: Galilée, 2003. p. 59-83.

CREPON, M. Langues sans demeure. Paris: Galilée. 2005.

DERRIDA, J. Edmond Jabès et la question du livre. In: __. L'écriture et la différence. Paris: Seuil, 1967. p. 99-116.

DERRIDA, J. Circonfession. In: DERRIDA, J.; BENNINGTON, G. (Org.). Jacques Derrida. Paris: Seuil, 1991.

DERRIDA, J. Le monolinguisme de l'autre - ou la prothèse d'origine. Paris: Galilée, 1996.

DERRIDA, J. Apories: mourir - s’attendre aux “limites” de la vérité. Paris: Galilée, 1997.

DERRIDA, J.. Fichus. Paris: Galilée, 2002.

DERRIDA, J. Abraham, l'Autre. In: COHEN, J.; ZAGURY-ORLY, R. (Org.). Judéités - questions pour Jacques Derrida. Paris: Galilée, 2003. p. 11-42.

\footnotetext{
${ }^{33}$ DERRIDA. Abraham, l'Autre, p. 29.
} 
DERRIDA, J. Seminario de Barcelona. In: SEGARRA, M. (Org.). Hélène Cixous y Jacques Derrida - lengua por venir/langue à venir. Barcelona: Icaria, 2004. 